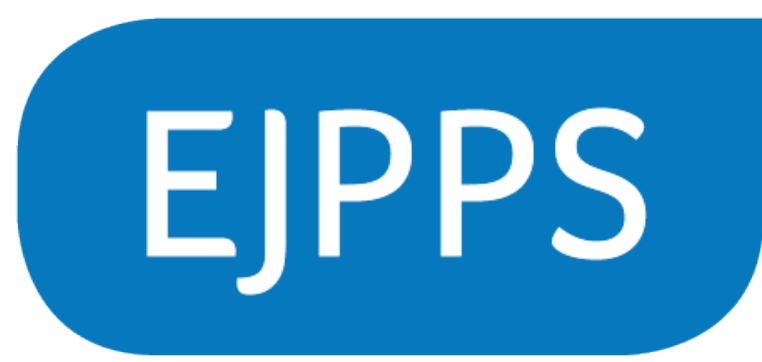

\begin{tabular}{|l} 
EUROPEAN JOURNAL OF \\
PARENTERAL AND \\
PHARMACEUTICAL SCIENCES
\end{tabular}

EJPPS - European Journal of Parenteral and Pharmaceutical Sciences Volume 25 Issue 3

https://www.ejpps.online/settleplatesandannex1

https://doi.org/10.37521/ejpps25303

Opinion Paper

Settle plates and Annex 1

Andrew Whittard Cherwell Laboratories Ltd

Corresponding Author: Andrew Whittard, Cherwell Laboratories

7 \& 8 Launton Business Centre, Murdock Road

Bicester,

Oxfordshire

OX26 4XB

Email: andrew.whittard@cherwell-labs.co.uk

Tel 01869355500 


\section{Settle plates and Annex 1}

The humble settle plate - $90 \mathrm{~mm}$ Petri dish - has been a mainstay of environmental monitoring within pharmaceutical manufacturing for decades. The standards for cleanrooms and Good Manufacturing Practice (GMP) stipulate limits for compliance using the settle plate.

The proposed revision to Annex 1 that has been in existence for several years now, does place greater focus on the microbial element of cleanroom qualification and routine monitoring. The current annex 1, from 2008, does not refer to microbial monitoring as part of the cleanroom qualification process, relying solely on particle size concentration (see 4.1). This places the guidance at odds with reality and out of step with what industry actually deploys; the extended detail in the new draft must be seen as a welcome improvement.

The current 2008 Annex 1 describes cleanroom classification in Section 4, and only mentions microbial monitoring in paragraphs 18,19 and 20 . When considering the relevance of viable particle data in relation to cleanroom operations, this is quite clearly a significant shortfall in the soon to be replaced guidance.

The revised Annex 1 (2020) draft describes microbial contamination and environmental monitoring in greater detail in sections 4 and 9, through paragraphs 4.33 and 9.24 to 9.33. And there are some significant differences in the text as well as subtle changes in wording.

The most obvious difference between the 2008 version and the draft 2020 version is in the limits for a Grade A space. The 2008 version stated an average of less than 1 which of course suggests if you have 9 out of 10 plates with one cfu/plate you are compliant. Quite clearly this would not be acceptable and defendable during an inspection. The $2020 \mathrm{draft}$ stipulates zero as the target for grade A compliance, however, a consequence of this is could be an increase in the occurrence of deviations and investigations which are timely and costly and ultimately put at risk product release. To minimise this risk, greater focus should be placed on EM methods and processes.

More subtle differences include the greater emphasis on risk assessment, a common theme in the $2020 \mathrm{draft}$, for example, defining the number of sampling locations based on risk.

The new draft has, as already mentioned, a section on qualification that includes microbial monitoring and mentions new technologies that might give differing results, as well as the need to justify why one of the stated methods has not been used. Whilst this opens up the opportunity to use new methods, these clearly will require an extensive amount of work and detailed validation.

Finally, back to the humble settle plate, both versions of Annex 1 mention the use of settle plates and both have notes about exposure time. The 2008 text says 'Individual settle plates may be exposed for less than 4 hours' (para 18 Note (a)) whereas the 2020 draft states 'Settle plates should be exposed for the duration of operations and changed as required after 4 hours. Exposure time should be based on recovery studies and should not allow desiccation of the media used' (para 4.33 note (a)). This change in text appears to demonstrate a shift in focus, there is an expectation that settle plates are exposed for 4 hours, however if this presents a risk to viability of the media and therefore the sample, an alternative exposure time must be considered and validated.

The increased text describing microbial monitoring from a half page to one and half pages and a much greater emphasis on a risk-based approach are welcomed improvements for all microbiologists. 